\title{
Franklin Delano Roosevelt: The Diagnosis of Poliomyelitis Revisited.
}

John F. Ditunno, Jr

Thomas Jefferson University

Bruce E. Becker

University of Washington

Gerald J. Herbison

Thomas Jefferson University

Follow this and additional works at: https://jdc.jefferson.edu/rmfp

Part of the Rehabilitation and Therapy Commons

Let us know how access to this document benefits you

\section{Recommended Citation}

Ditunno, Jr, John F.; Becker, Bruce E.; and Herbison, Gerald J., "Franklin Delano Roosevelt: The Diagnosis of Poliomyelitis Revisited." (2016). Department of Rehabilitation Medicine Faculty Papers. Paper 44.

https://jdc.jefferson.edu/rmfp/44

This Article is brought to you for free and open access by the Jefferson Digital Commons. The Jefferson Digital Commons is a service of Thomas Jefferson University's Center for Teaching and Learning (CTL). The Commons is a showcase for Jefferson books and journals, peer-reviewed scholarly publications, unique historical collections from the University archives, and teaching tools. The Jefferson Digital Commons allows researchers and interested readers anywhere in the world to learn about and keep up to date with Jefferson scholarship. This article has been accepted for inclusion in Department of Rehabilitation Medicine Faculty Papers by an authorized administrator of the Jefferson Digital Commons. For more information, please contact: JeffersonDigitalCommons@jefferson.edu. 
FRANKLIN DELANO ROOSEVELT: THE DIAGNOSIS OF POLIOMYELITIS REVISITED

AUTHORS:

John F. Ditunno, JR., MD

Bruce E. Becker, MD

Gerald J. Herbison, MD

\section{ABSTRACT:}

Revisiting the ailments of famous historical persons in light of contemporary medical understanding has become a common academic hobby. Public discussion of Franklin Delano Roosevelt's (FDR) diagnosis of poliomyelitis following his sudden onset of paralysis in 1921 has received just such a revisitation. ${ }^{1}$ Recently, this 2003 historical analysis has been widely referenced on the Internet and in biographies raising speculation that his actual diagnosis should have been Guillain-Barre Syndrome, a non-contagious disease of the peripheral nervous system rather than poliomyelitis. The authors of that 2003 analysis used a statistical analysis of his case by selectively choosing some of his reported symptoms. ${ }^{1}$ However, FDR's diagnosis of poliomyelitis was fully supported by the findings of leading expert physicians of that time who were very knowledgeable in the then-common disease and who periodically examined him during the period of 1921-1924. The most significant diagnostic features of polio are the absence of objective sensory findings in the presence of flaccid motor paralysis. These features are consistent with diagnostic criteria extant during the periods of major poliomyelitis epidemics as well as those of the Center for Disease Control 90 years later. Additional findings of fever, prodromal hyperesthesia, more severe residual proximal muscle weakness, and extensive lower extremity impairment requiring mobility with long leg braces or a wheelchair gives further evidence for the diagnosis in FDR's case. Non-bulbar Guillain-Barre Syndrome, which shares the features of a flaccid paralysis thus mimicking the initial presentation of poliomyelitis, has over an $80 \%$ complete recovery with no reported cases of eventual wheelchair use. The most severe cases of Guillain-Barre Syndrome often have persistent objective sensory loss, associated with greater weakness in the feet and hands, which show no resemblance to Roosevelt's impairment and disability. In light of the expert initial assessments by physicians completely familiar with the signs and symptoms of the then-common disease, review of his initial and subsequent disease course, and residual symptoms in comparison with those of Guillain-Barre syndrome, we find no reason to question the diagnostic accuracy of poliomyelitis, and wish to put this debate to rest. 


\section{INTRODUCTION}

In recent decades, the popularity of retrospective analysis of the medical history of historical figures has received significant public attention. Such efforts have been made by medical historians, general historians and the media, and some of these efforts have become popularily accepted. ${ }^{2}$ One such example of this is the attribution of Marfan's Syndrome to Abraham Lincoln, which despite controversy, has received common acceptance. ${ }^{3-5}$ Pertinent to this paper, it has been over 90 years since Franklin Delano Roosevelt (FDR) experienced the onset of paralysis in the summer of 1921, but only in the past decade have the features of his illness, and the historical impact of his illness on disability and heathcare, been systematically scrutinized. In the vein of retrospective diagnosis, a 2003 paper published in the Journal of Medical Biography analyzed some of FDR's clinical symptoms and course using Bayesian statistical analysis of probability, concluding that a more probable diagnosis than poliomyeitis was that of GuillainBarre Syndrome. ${ }^{1}$ This paper has received considerable recent attention, even being referenced in the Wikipedia listing of FDR and his polio diagnosis, ${ }^{6}$ other website listings, ${ }^{7}$ a recent biography from James Tobin - a National Book Critics Circle Award historian, ${ }^{8}$ and being referenced in the 2006 Pulitzer Prize winning history, Polio: An American Story. ${ }^{9}$ Despite this current speculation, retrospective diagnosis has many limitations. ${ }^{2}$ The authors of this paper have reviewed the missing critical pieces of information from that 2003 retrospective, and will show how the inclusion of that data dramatically supports the conclusion that FDR contracted poliomyelitis and that his subsequent symptoms were classic for that disease.

\section{FDR's Polio Diagnosis and Its Broad Repercussions}

Papers by physicians regarding Franklin Delano Roosevelt's illness, restoration of function and his founding of Georgia Warm Springs Foundation have written that his legacy has had a profound influence on the development of the medical specialties of Orthopedic Surgery ${ }^{10}$ and Physical Medicine and Rehabilitation. ${ }^{11,12}$ The impact of his illness extended far beyond medicine, dramatically raising public concern of poliomyelitis across the highly populated Northeastern and Midwestern cities of the nation which had seen several epidemics during the preceding decades, including a major outbreak in New York City in 1916, the year in which the total number of national cases numbered 29,000. ${ }^{9,13}$ Roosevelt's course of treatment was directed by his physician Robert Lovett, professor of surgery at Harvard and then the leading national expert on poliomyelitis. As his recovery progressed, FDR began to explore more effective treatments for the disease, in the process becoming an expert on the then-current state of the art of medical and rehabilitative care. ${ }^{14}$ Roosevelt, through his work with Lovett, became a believer in the value of warm water therapy. In 1924, FDR journeyed to Warm Springs, GA at the invitation of his friend, the Wall Street banker George Foster Peabody who was a part owner of a warm spring spa there. ${ }^{14}$ Peabody had described to FDR the beneficial impact of those hot springs on a young man with polio. While there, Roosevelt began a regimen of swimming three times a day, and by the end of that stay felt he had developed improved strength. ${ }^{11}$ Newspaper reports of his improvements were published in the Atlanta Journal, producing a flood of national interest and visitors to the Warm Springs facility. ${ }^{11}$ FDR became a tutor to the many polio survivors who came there, instructing them in exercises, and recorded the gains seen in these 
individuals for review by skeptical physicians. ${ }^{15}$ Against the advice of his wife and financial advisors, FDR purchased the Warm Springs property in 1926, expanding its lodging capacity and facilities. In the process he created what was at that time the first comprehensive rehabilitation hospital, featuring physical, occupational, and recreation therapies, as well as bracing and orthotic care, and social services. ${ }^{11}$ (Fig. 1) By 1940, Warm Springs housed 400 residents in a truly architecturally accessible facility, the first in the nation. ${ }^{11}$ FDR was a tremendous fundraiser for the facility, and his ascendency to the Presidency in 1932 only raised this visibility. In 1938, he and his former law partner, Basil O'Connor, created a separate foundation to create a national program to combat polio, the National Foundation for Infantile Paralysis (NFIP.) ${ }^{11}$ The NFIP and its very potent fund-raising arm, the March of Dimes became "by a wide margin the single most popular medical cause in the post-war period," and was critical in funding the medical research that resulted in the creation of polio vaccines. ${ }^{16}$ Roosevelt through his own experience and that of Warm Springs came to fully understand the role that comprehensive rehabilitation could play, not just in polio survivors but also in wounded veterans and civilians. In 1943, President FDR signed into law a bill creating the Office of Vocational Rehabilitation under the Federal Security Agency, creating comprehensive vocational rehabilitation programs for both veterans and civilians, each under different oversight structures. ${ }^{15}$ The results of his illness were to have a profound impact not just on on FDR's life but far beyond.

\section{The Literature and the Controversy}

Two papers authored by physicians in recent years have reported on FDR's immediate onset of paralysis, diagnostic considerations and his progress through rehabilitation. ${ }^{1,17}$ One of the papers questions the diagnosis of poliomyelitis and offers a rationale for the diagnosis of Guillain-Barre Syndrome (GBS) based on a statistical interpretation of some of his symptoms and physical findings reported in letters and medical records. ${ }^{1}$ That same paper states that "other aetiologies of flaccid paralysis ...were unknown," despite referencing Landry's ascending paralysis as being mentioned in Lovett's 1916 textbook on poliomyelitis. ${ }^{1}$ An extensive literature describing the signs and symptoms of acute ascending paralysis dates from at least 1859 , the year Landry published his detailed report of an afflicted individual. ${ }^{18}$ Westphal in 1876 described the differences between what he then termed "Landry's ascending paralysis" and poliomyelitis, and 4 years later, Leyden divided the two clinical entities as separate, both clinically and pathologically. ${ }^{19,20}$ The existence of Landry's ascending paralysis (later to be labelled as Guillain Barre Syndrome) was certainly known to expert physicians such as Lovett and Draper. The conclusions of that same paper questioning FDR's diagnosis of polio ${ }^{1}$ have been reported in considerable detail in lay citations. ${ }^{6,8,9}$ Although an effort to reexamine the evidence by calculation of probabilities based on interpretation of findings from letters and lay publications is interesting, it does not substitute for the accurate description and analysis by FDR's clinicians who observed his illness first hand and were pre-eminent experts in the disease. It fails the test of validity described by Karenberg in his paper on medical historiography. Karenberg states, "retrospective diagnosis...runs the risk of restricting the understanding of history to a biologic process. If done in this way it is abused." 21 The findings and impression of those experts in poliomyelitis who examined and cared for FDR in 1921, felt the diagnosis of Roosevelt's paralysis was neither difficult nor seriously in question. ${ }^{22}$ Dr. Robert Lovett was the nation's foremost authority in the diagnosis and treatment of poliomyelitis, and author of the definitive textbook on the disease. ${ }^{23}$ In 1922 he published a definitive article in JAMA on the diagnosis and 
treatment of polio based upon his personal study of 5100 patients for which he cared between 1916 and that date. ${ }^{24}$ After his initial examination of FDR, Lovett wrote about FDR's diagnosis to another expert in both basic polio research and clinical care, Dr. George Draper under whose care FDR would be entrusted in several weeks, "I thought it perfectly clear so far as the physical findings were concerned." ${ }^{23}$ Lovett wrote in 1922 that the diagnosis could usually be made solely from the physical findings. ${ }^{24}$

In resolving this newly contrived controversy, we believe that there is value to revisiting the diagnostic and prognostic features of FDR's illness, based on a careful review of the objective physical findings recorded by his physicians and therapists during the initial years of his illness. The primary purpose of this paper, therefore, is to present objective evidence recorded by experts in the disease through numerous examinations of Mr. Roosevelt over at least a 3-year period. A secondary purpose is to confirm that the objective evidence of the diagnosis, prognosis and outcome of FDR's illness are far more characteristic of poliomyelitis than Guillain-Barre Syndrome.

\section{METHOD}

A literature review employed an electronic search of publications in journals and textbooks, supplemented by hand searches of the older literature in the early half of the $20^{\text {th }}$ century prior to the discovery of polio vaccines. The search encompassed data on incidence of poliomyelitis (polio), the presentation and clinical course in children and adults, diagnosis, prognosis, outcomes, and rehabilitation. The same topics were searched in regard to Guillain-Barre Syndrome (GBS). Symptoms, physical findings and other clinical features as listed in the results section were searched by hand and electronically. The research was further supplemented by extensive archival library research compiling actual correspondence between FDR's treating physicians and therapists, as well as some family letters.

Data is presented in a case report of the clinical features regarding the diagnosis and prognosis of Franklin D. Roosevelt's illness from August 10, 1921 until February 1924. The results of this search are analyzed and tabulated in a table to illustrate the similarities and differences between the important clinical features of the FDR case report, poliomyelitis and GBS. The frequency of the clinical features in Table 1 reflect percentages from case series, although estimates were necessary in the context of bulbar paralysis. Bulbar polio and bulbar GBS are known to have more severe outcomes, which required extrapolation as patients with a history of ventilator use were excluded from the estimates of severity of disability and will be identified in the results/discussion sections.

\section{FDR CASE REPORT}

The following case report will emphasize those findings reported by the clinicians (so noted by the authors of this paper in italics) who examined FDR. The italics will be further emboldened in the first paragraph, which represents Lovett's notes of the onset for the period of August 10 to 14, 1921 prior to his examination of FDR on August 25, $1921 .^{25}$ 
FD Roosevelt at age 39 developed malaise on August $10^{\text {th }}$ after bathing in Lake Glen Severn on Campobello Island in Canada. The following day, August 11 the pain was so severe in "his back and legs" that Dr. Bennett from Lubec, Maine was called by Eleanor Roosevelt. ${ }^{26}$ On August 12 both legs (were) weak accompanied with urinary retention. On August 13 he had to be helped to walk and was completely paraplegic. On August 14 he was seen by Dr. Keen, who after a "most careful thorough examination" that morning and the following morning indicated that FDR's problem had resulted in "removing the power to move (his legs) though not to feel," as reported in a letter from Eleanor Roosevelt to James Roosevelt. ${ }^{26}$ Keen sought the opinion of Dr. Lovett, when the family indicated that they wished a second opinion. Lovett arrived at Campobello 15 days after the onset, August 25th, recorded the above historical features and examined the patient.

Lovett documented the findings that support his diagnosis of polio in two letters from his examination on August 25, 1921..$^{22,27}$ On Sept 12 he reported his history and physical findings gained on August $25^{\text {th }}$ :

"he went down there very tired, took a bath, went swimming and stayed there a good while. He ran home in his wet bathing suit and subsequently had chills, high temperature and pain. Questioning however showed that there had been hyperesthesia of the legs preceding the bath (swim) for a day or two". "He was tender, when I examined him ...so my examination had to be superficial. He had...facial involvement, apparently no respiratory, but weakness in the arms ... not grouped at all. There was some atrophy of the left thenar eminence... His bladder was paralyzed...scattered weakness in the legs, most marked in the hips...."22

Dr. Bennett became concerned and sent a telegram on Aug 31, 3 weeks following the initial attack to Lovett followed by a letter the following day indicating that "the atrophy has increased and power lessened. Bladder and bowel function remains impaired, the muscles are flabby and there is evidence of hyperesthesia over the thighs. There has been improvement of muscle power above the waist but not below,"(again, italics ours) ${ }^{28}$ On September $8^{\text {th }}$, Bennett updated Lovett of mild temperature elevations (99.5 to 100.5 degrees F) from September $4^{\text {th }}$ through September $8^{\text {th }}$ (4 weeks following onset) associated with increased leukocytes in the urine several days before FDR's pending transfer to NYC. ${ }^{29}$ FDR was transferred to NYC under the care of Dr. George Draper at Presbyterian Hospital on September 13, 1921, when he entered the admitting diagnosis of “anterior poliomyelitis" into FDR's medical chart. ${ }^{30}$ Draper noted that FDR had pain and severe paralysis particularly in the lower extremities. He documented asymmetrical weakness in the upper extremities with involuntary twitching in the forearm muscles (fasciculations), but refrained from a complete examination of the arms to spare the patient further anxiety. Draper reported his findings to Lovett:

"marked falling away of the muscle masses on either side of the spine in the lower lumbar region...(and) buttocks. ....marked weakness of the posterior part of the left deltoid; very marked weakness of the right triceps; and an unusual amount of gross muscular twitching of both forearms. ...coordination of fine muscles of the hands very well... the biceps... good so...he can pull himself up by a strap. "little motion...long 
extensors of the toes of each foot; a little in the perinea of the right side; little ability to twitch the bellies of the gastrocnemii, but not really extend the feet. There is little slight power in the left vastus...voluntary twitching of the hamstring masses. ${ }^{31}$

Draper apprised Lovett of the resolving muscle tenderness and extent of back, pelvic and leg muscle paralysis on October 11, close to 9 weeks following the onset:

"he still has a little tenderness in his ham strings...much more power in the back muscles than I thought...but...pelvic girdle...thighs...most of the leg muscles are in poor shape." ${ }^{\prime 32}$

Lovett visited FDR at "Roosevelt Hospital" and wrote to Dr. Bennett on October 17 stating that FDR was sitting up but was still "tender in spots" remarking that he had power in all hip muscles. Lovett approved his discharge home whenever the patient wished to go. ${ }^{33}$

In December 1921 Lovett approved of progressive exercises following his receipt of a letter from the physical therapist, Kathleen Lake, apprising Lovett of her findings. ${ }^{34}$ In her letter she stated that there were knee flexion contractures and there was still some "sensitiveness of the gastrocnemii...but all the soreness has gone from his back" ${ }^{34}$ Dr. Lovett ordered serial casting to correct the knee flexion contractures and was informed the program had begun. ${ }^{35}$ Apparently the progression of the serial casting was rather aggressive (4 wedges in 22 hours) according to the physical therapist and "sensitiveness" returned to the calf muscles accompanied by "weakness." ${ }^{36}$ In May 1922 Draper and Lovett agreed that FDR needed to be admitted to the Phillips House in Boston for a complete reassessment including accurate manual muscle testing (MMT), prescriptions for new braces and ambulation training. Roosevelt was subsequently admitted to the Phillips House on May 31 and Dr. Lovett and his staff performed a complete MMT on June 1, 1922, approximately 10 months following the onset of FDR's paralysis.

The MMT on June 1, 1922, was repeated by Lovett and his staff in $1923^{37}$ and was published in modified format in 2002 in the American Journal of Physical Medicine and Rehabilitation (Table 1). ${ }^{17}$ Draper's last letter to Lovett was written on February 1, 1924, stating that in his opinion FDR had "reached the limit of his possibilities." ${ }^{38}$ Dr. Lovett died in July of that year at the age of 64 .

\section{RESULTS}

Table 2 reflects the results of the case study and literature search. ${ }^{24,39-50}$

\section{DISCUSSION}

The diagnosis and prognosis of polio based on the records of physicians and therapists who examined FDR during his illness requires an understanding of the criteria used at that time. In 1922, the year following his initial examination of FDR, Lovett published his diagnostic criteria based on his observation of over 5,000 cases. Lovett summarized his diagnostic criteria as follows: 
(1) a scattered, irregular, widely spread loss of motor power on one or both sides;

(2) no diminution of sensation in affected parts, and

(3) diminution or loss of reflexes in the parts affected. ${ }^{24}$

The recent Center for Disease Control case definition for paralytic poliomyelitis identifies the same features; "Acute onset of a flaccid paralysis of one or more limbs with decreased or absent tendon reflexes in the affected limbs, without other apparent cause, and without sensory or cognitive loss." 43

The symptoms and signs described in the case report of FDR's onset in August of 1921 and subsequent course will be assessed in the context of Lovett's criteria and other experts in poliomyelitis. ${ }^{45,46,51}$ The diagnosis/prognosis features of polio in general, and in FDR's case report in particular, will be contrasted with the features of Guillain-Barre Syndrome. ${ }^{41,48,52-54}$

\section{Adult features}

Adults have a higher incidence of severe pain on day one, usually in the lumbar region with a higher incidence of prodromal hyperesthesia. ${ }^{47}$ These three features were clearly present in FDR's case. Children have a much greater frequency of monoplegia, with a recorded incidence of 85 to $91 \%$ in over 500 cases of spinal paralytic polio. ${ }^{55}$ This pattern in children is likely the basis for the criterion of asymmetry cited in the literature. ${ }^{56-58}$ Adults over the age of 30, however, have four extremity paralysis in over 50\% (74/ 141) cases, which was the pattern in FDR's case. Bladder paralysis "a common feature in adults $(>40 \%) \ldots$ is most infrequent in children (2-4\%.)"59

\section{Fever}

Lovett recorded the history of "chills, high temperature and pain" the evening prior to the onset of muscle weakness. The presence of fever is unusual in Guillain-Barre Syndrome (GBS) and is listed as one of the features important in the differential diagnosis between polio and GBS. ${ }^{42}$

\section{Hyperesthesia and other sensations}

Authorities on the diagnosis and treatment of polio such as Lovett, Draper and Horstman recognized cutaneous hyperesthesia as a prominent symptom of polio. They indicated, however that the characteristic feature of the diagnosis was the absence of sensory loss. Draper regarded hyperesthesia as "the most characteristic symptom" of polio if it occurred during an epidemic. ${ }^{60}$ He described the findings as increased sensitivity of the skin (hyperesthesia) that may be elicited by rubbing the skin and distinguished it from muscle tenderness, which was elicited by squeezing the muscle. ${ }^{45}$

Lovett referred to the term "hyperesthesia" several times in his correspondence with Draper and Bennett regarding FDR's clinical course. When Bennett reported FDR's continued hyperesthesia over the thighs at 3 weeks after onset, Lovett advises Bennett that "massage will prolong hyperesthesia... and the thigh sensitiveness should be watched from this point of view." As 
illustrated in this comment to Bennett, Lovett used sensitiveness as synonymous with hyperesthesia. In his 1922 paper on diagnosis he lists "no diminution of sensation" as one of the 3 diagnostic features of polio, but refers to the following signs and symptoms: "in practically all cases ${ }^{61}$ is accompanied by marked tenderness, sensitiveness and pain in the affected parts."

Kathleen Lake, who was trained by Lovett, used sensitiveness in describing the presence at 4 months and after aggressive stretching of FDR's knee contractures. ${ }^{34,62}$ FDR used this term sensitiveness in describing his discomfort in $1924 .{ }^{63}$ A specific reference to "cutaneous hyperesthesia" is listed in Brain's Diseases of the Nervous System 2009 description of polio. ${ }^{44}$

FDR is reported to have complained of his legs feeling numb during the initial onset, but there were never findings of sensory loss by any of the physicians who examined him and Keen was quoted as saying that he lacked power but not feeling. Lovett again in his paper on diagnosis states, "The attack may be preceded by queer sensations in the parts to be affected, such as prickling or numbness." 24 This early symptom of numbness was not evidence of sensory loss by physical examination. It is inconceivable that Lovett and Draper found sensory loss on numerous examinations of FDR, as both were aware that absence of sensory findings was diagnostic of polio and was referenced in their publications 24,64

\section{Pain}

Intense pain in the back and legs was an important feature of polio at the onset, particularly in adults. $^{47,51}$ FDR's complaint of intense pain in the back and legs was the reason Eleanor Roosevelt called for Dr. Bennett on August $11^{\text {th }}$ prior to the onset of leg weakness, ${ }^{26}$ and was recorded by Lovett in his notes on FDR. ${ }^{22}$ Russell used the severe onset of pain in the back and legs as equivalent to meningeal irritation during onset in a polio epidemic. ${ }^{51}$

\section{Tenderness}

Lovett emphasized the importance of muscle tenderness as a diagnostic and prognostic feature and that "tenderness of the parts to be affected occurs early and may be excessive." 24 Tenderness is such a prominent feature of the affected muscles in the acute phase that Lovett refrained from precise muscle testing because in his opinion it risked further muscle damage. Draper indicated his concern over the persistence of tenderness at 6 weeks and continued tenderness of the muscles at 2 months, which was confirmed by Lovett the following week. ${ }^{65}$ The average duration of tenderness according to Lovett's experience was 6 weeks and this deadline was already past. ${ }^{24}$ Because Lovett did not commence exercises during the acute phase (duration of muscle tenderness), he must have been satisfied that the tenderness was gone in mid-December (16 weeks) when he initiated exercises and physical therapy.

\section{Muscle weakness}

The pattern of muscle weakness from the time of onset to maximum paralysis was a period that typically ranged from 1-6 days. ${ }^{64}$ This progression to maximum paralysis in FDR's case, 
317 however, is not documented by expert clinical examination between Keen's findings on the $3^{\text {rd }}$

318 day and Lovett's examination at 2 weeks. ${ }^{22}$

319 In his 1922 paper on poliomyelitis, Lovett reported that the typical pattern of the extremities

320 involved and their symmetry was "roughly symmetrical" with the lower extremities more often

321

322

323

324

325

326

327

328

329

330

331

332

333

334

335

336

337

338

339

340

341

342

343

344

345

346

347

348

349

350

351

352

353

354

355

356 involved that the uppers. ${ }^{24}$ While $70 \%$ involved one or more extremities unilaterally there was a $25-30 \%$ involvement of both legs and was slightly higher bilaterally (10\%) in New York State. ${ }^{66}$ FDR's involvement was roughly symmetrical. He had asymmetry of the deltoid, triceps and vastus lateralis . ${ }^{31}$ His lower extremity involvement (Table 1) shows involvement of both legs, more severe in the proximal muscles and less severe in the the feet. These finding of "roughly symmetrical" are consistent with Lovett's experience. In adults, the involvement of both legs and arms has been reported to be as high as 50\% in epidemics in Massachusetts in the 1950s, in contrast to children in which monoplegia (asymmetry) is the typical pattern. ${ }^{55,59}$

The severity of the paralysis similar to FDR's case, which would require ambulation with long leg braces and/or a wheelchair is from 6-20\% in acute cases, but these findings reflect reports on post-polio studies, which are not population based. ${ }^{67}$ An epidemic in 1941 reported asymmetry in those with residual moderate paralysis $27 / 32$, but symmetry in severe paralysis $20 / 20 .{ }^{68}$ In over 64,000 cases of paralytic polio reported to the National Foundation from the years 1952-1956, the percentage of persons with some residual paralysis of both legs was $45 \%$ and severe paralysis of both legs of $15 \% .^{69}$

The "weakness in the arms...not grouped" and the "scattered weakness" in the arms and legs had great significance to Lovett, because he regarded this pattern of muscle weakness as he described in FDR's case to represent poliomyelitis as the only diagnostic possibility in an acute onset of motor flaccid paralysis. ${ }^{22,24}$ "There is no other widely distributed lesion which picks out motion alone and leaves sensation untouched."24 "Only a lesion of the anterior horn cell" will produce the clinical picture described in Lovett's examination. ${ }^{24}$ The involuntary "twitches of forearm muscle" observed by Draper is also consistent with the fasciculations seen in other anterior horn cell diseases such as post-polio syndrome, amyotrophic lateral sclerosis and primary muscular atrophy. ${ }^{56}$

The prognostic significance of the pattern of weakness and final recovery in FDR's case is completely consistent with the diagnosis of polio. FDR had profound weakness of the proximal muscles of the hips and thighs, which failed to improve more than one muscle grade from a trace $(1 / 5)$ to poor (2/5) muscle grade over 11 year. Sharrard offers the pathophysiologic explanation as to why proximal muscles are more involved. ${ }^{50}$ Sharrard's concept of motor cell column damage in the spinal cord fits with the "scattered" muscle weakness found by Lovett as manifestations of anterior horn cell origin rather than peripheral neuropathy. ${ }^{70}$

\section{Muscle Atrophy.}

Atrophy of specific muscles, when it had relevance to the diagnosis of polio is listed in Lovett and Draper's letters. In particular "atrophy of the left thenar eminence" was a frequent occurrence in polio and "throws light on diagnosis of doubtful cases." 22 Lovett documents "some atrophy of the left thenar eminence" in his initial examination of FDR. Draper expresses concern 
to Lovett regarding the "marked falling away of muscles masses ... [of the] buttocks" and other proximal muscles on Sept 24, 1921. The profound atrophy of the buttocks and thighs are illustrated in Figure 2 (FDR in bathing suit lateral view) in 1924, 3 years after the onset of FDR's paralysis. This marked degree of atrophy correlates with the profound proximal muscle weakness recorded in the MMT by Lovett in 1922 and is unchanged in 1923 (Table 1). The marked wasting of the thighs in Figures $3 \&$ 4, in 1932 illustrates the permanent features of FDR's proximal muscle disease, typical of polio and rarely seen in polyneuropathies such as GBS.

\section{Facial and Bladder paralysis.}

Lovett indicates that facial paralysis was "not uncommon." In the spinal form of polio in one series unilateral transient facial paralysis occurred in 5/66 cases. ${ }^{71}$ Nor does the duration of the bladder paralysis for a period of two to three weeks seem an issue of concern for Lovett as he assures Bennett 20 days post onset that "urinary retention is typical in this type of case" particularly in patients with abdominal and/or pelvic girdle weakness, which Lovett document's in FDR's case. ${ }^{72,73}$ With paralysis of abdominal and pelvic muscles it would be more difficult to compress bladder contents resulting in prolonged urinary retention. In adults, bladder paralysis is much more frequent and was present in $44.4 \%$ of individuals age $40-60$, which often required catheterization. ${ }^{55}$

\section{GBS vs POLIO}

The authors of the 2003 paper $^{1}$ employed Bayesian probability analysis, which has been proffered by them as an analytical approach to achieve more accuracy in clinical judgment of differential diagnosis than methodical diagnosis by experienced clinicians. The authors make a serious attempt to employ this approach by calculating the anterior and posterior probabilities based on a retrospective analysis of clinical features as stated above. Their analysis, however, contains serious flaws in symptom omission, inclusion and interpretation. Those errors may be due to the authors' lack of awareness of the differences between the infantile and adult forms of polio, the characterization of symptoms/signs, simple oversight, or other unknown reasons.

Important symptoms and signs such as muscle soreness and sensory loss on physical examination are missing from their list in Table $3^{1}$ Muscle soreness is a major factor in acute polio, but typically abates by two months. Muscle soreness is far less common in GBS (10\%) but when present tends to persist. ${ }^{18,52}$ Physical findings of sensory loss, which are absent in polio, are typical in GBS and may also persist for years. ${ }^{48,74}$ None of FDR's physicians reported sensory loss and on physical examination and his symptoms of hyperesthesia had cleared at six months.

Of 11 clinical features listed in Table $3^{1}$ only two (fever and permanent paralysis) are listed as favoring polio. Many of the remaining 9 features are flawed, such as listing FDR's progression of paralysis at 10-13 days. Lovett's notes indicate that by August $13^{\text {th }}, 3$ days after symptom onset he had become paraplegic, and Keen reported on August $14^{\text {th }}$ that he "had lost the ability to move his legs though not to feel." ${ }^{26}$ Another feature, dysesthesia is listed as absent in polio, 
illustrating a lack of awareness of the literature (Lovett; Draper; Horstman) regarding the typical presence of hyperesthesia/sensitiveness in polio as well as the clinical observations by the clinicians who examined FDR and reported on his hyperesthesia/sensitiveness. ${ }^{24,45,46}$ It appears that the authors of the 2003 paper may have interpreted symptoms of cutaneous hyperesthesia, common in polio, with the dysesthesias associated with GBS. Another error within their 9 listed factors is bladder paralysis, which is described as lasting 1-3 days in polio. Lovett offers the association of abdominal, pelvic floor and girdle paralysis as features associated with prolonged urinary retention in polio. ${ }^{24}$ The patterns of recovery that clearly distinguish polio from GBS in general, and especially in FDR's case, are the major differences in residual proximal muscle weakness in polio contrasted to distal weakness in GBS. ${ }^{47,48,50,69,70}$ Finally, the severity of the FDR's impairment and wheelchair mobility, which may occur in up to $20 \%$ of the polio population, is not reported in non-bulbar GBS. ${ }^{52,74}$ In our opinion, the sum of these errors dramatically alters the statistical analysis as held true by Goldman et al.

\section{CONCLUSIONS:}

It is apparent in reviewing FDR's initial clinical presentation, subsequent medical management, and his partial recovery, that the diagnosis of poliomyelitis was neither made casually, nor by physicians and therapists unfamiliar with this then-common disease. He was evaluated and subsequently cared for by the nation's leading experts in the disease. Virtually every one of his initial symptoms were examples of common findings and complaints seen in the adult-onset form of the disease, which while less common than the infantile form, in 1921 was still very much a disease to be feared. While GBS is a diagnosis with some commonalities with poliomyelitis, there are critical distinguishing factors that made the differentiation possible, even at a time when laboratory testing of cerebrospinal fluid was uncommon. A statistical analysis of diagnostic probabilities is not valid when several of these significant distinguishing factors are omitted from such an analysis. A careful inclusion of all symptoms, the differentiating significance, and their presence or absence, is critical in drawing conclusions. There seems little reason to conclude anything other than the fact that Roosevelt contracted poliomyelitis following exposure in the late summer of 1921, had profound and permanent muscle function loss as the result of that disease, and despite that disability, became one of the most influential public figures of the $20^{\text {th }}$ century, both within our nation as well as across the globe during World War II.

The question of Franklin Delano Roosevelt's diagnosis may seem esoteric as a present-day issue, but is not simply an epistemological exercise. The management of acute and chronic polio was significantly enhanced by Roosevelt's work at Warm Springs, his close relationship with medical leaders, and his close associations with major philanthropists, federal power-brokers and his family connections. FDR's close relationship with Bernard Baruch, a major philanthropist of the time, aided the development of a major field of contemporary medicine, the specialty of Physical Medicine and Rehabilitation. As a consequence of his illness and lifelong disability, the very nature of how Americans viewed disability was changed, and the cure for polio was dramatically expedited improving the lives of millions the world over. The world is now close to the eradication of this disease, in large part because of the vaccines developed through research 
437 initially funded by the March of Dimes and Roosevelt's subsequent efforts as President of the 438 United States. It is time to put this controversy to rest.

439

440 
441 Acknowledgements:

442 The author (s) wish to acknowledge the assistance of Michael Shadix, archivist, Professional

443 Library Roosevelt Institute, Warm Springs, Georgia and Jack Eckert, Public Services Librarian,

444 Harvard Medical School Countway Library of Medicine, Boston, Massachusetts.

445 
448

449

450

451

452

453

454

455

456

457

458

459

460

461

462

463

464

465

466

467

468

469

470

471

472

473

474

475

476

477

478

479

480

481

482

483

484

485

486

487

488

489

490

491

\section{Bibliography}

1. Goldman AS, Schmalstieg EJ, Freeman DH, Jr., Goldman DA, Schmalstieg FC, Jr. What was the cause of Franklin Delano Roosevelt's paralytic illness? J Med Biogr. Nov 2003;11(4):232-240.

2. Rushton AR. Diagnosing the dead: the retrospective analysis of genetic diseases. $J R$ Coll Physicians Edinb. 2013;43(1):11-14.

3. Gordon AM. Abraham Lincoln--a medical appraisal. J Ky Med Assoc. Mar 1962;60:249-253.

4. Lattimer JK. Lincoln did not have the Marfan Syndrome; documented evidence. $N$ Y State J Med. Nov 1981;81(12):1805-1813.

5. Schwartz H. Abraham Lincoln and the Marfan Syndrome. JAMA. Feb 15 1964;187:473-479.

6. Franklin D. Roosevelt's paralytic illness. https://en.wikipedia.org/wiki/Franklin_D._Roosevelt Polio.

7. Veronese K. Franklin Delano Roosevelt probably didn't have polio after all. 2012; http://io9.com/5958933/franklin-delano-roosevelt-probably-didnt-have-polio-after-all.

8. Tobin J. The Man He Became: How FDR Defied Polio to Win the Presidency. New York City, New York: Simon \& Schuster; 2013:1-384.

9. Oshinsky DM. Polio : An American Story. New York, NY: Oxford University Press; 2005:1-342.

10. Friedenberg ZB. Franklin D. Roosevelt: his poliomyelitis and orthopaedics. J Bone Joint Surg Am. Jul 2009;91(7):1806-1813.

11. Verville RE, Ditunno JF, Jr. Franklin Delano Roosevelt, polio, and the warm springs experiment: its impact on physical medicine and rehabilitation. PM R. Jan 2013;5(1):1-290.

12. Becker BE. 46th Walter J. Zeiter lecture, exercise is rehabilitation medicine: our history and future. PM R. Apr 2015;7(4):345-353.

13. Fairchild AL. The polio narratives: dialogues with FDR. Bull Hist Med. Fall 2001;75(3):488-534.

14. Gallagher H. FDR's Splendid Deception. New York NY: Dodd, Meade; 1985.

15. Verville RE. War, Politics, and Philanthropy: The History of Rehabilitation Medicine. Lanham, Maryland: University Press of America, Inc.

16. Starr P. The Social Transformation of American Medicine. New York, NY: Basic Books, Inc; 1982:1-514.

17. Ditunno JF, Jr., Herbison GJ. Franklin D. Roosevelt: diagnosis, clinical course, and rehabilitation from poliomyelitis. Am J Phys Med Rehabil. Aug 2002;81(8):557-566.

18. Landry O. Nore sur la paralysie ascendante aigue. Gaz. hebd. med. chirurg. 1859;6(July, Aug):472474, 486-488.

19. Leyden E. Ueber Poliomyelitis und Neuritis. Ztschr. klin. med. 1880;1:387-484.

20. Westphal C. Ueber einige Fäile von acuter, tödlicher Spinallähmung (sogenannter acuter aufsteigender Paralyse). Arch. Psychiat. 1876;6:765-822.

21. Karenberg A. Retrospective diagnosis: use and abuse in medical historiography. Prague Med Rep. 2009;110(2):140-145.

22. Lovett RW. Letter Lovett, R. W. to Draper, G. Sept 12,1921Boston, Mass.: Francis A. Countway Library, Harvard Medical Library; 1921.

23. Paul JR. A History of Poliomyelitis. New Haven and London: Yale University Press; 1971.

24. Lovett RW. The diagnosis, prognosis and early treatment of poliomyelitis. JAMA. 1922;78(21):1607-1611.

25. Lovett RW. Lovett's handwritten notes, August 25th, 1921Boston, Mass.: Francis A. Countway Library; 1921. 
26. Roosevelt E. Letter Eleanor Roosevelt to James Roosevelt Roosevelt, August 14, 1921. In: Roosevelt E, ed. F.D.R. His Personal Letters: 1905-1928. New York: Duell, Sloan and Pearce; 1948:523-525.

27. Lovett RW. Letter R.W. Lovett to G. Draper, September 24, 1921Boston, Massachusetts: Francis A. Countway Library; 1921.

28. Bennett EH. Letter E.H. Bennett to R. W. Lovett, September 1, 1921Boston, Massachusetts: Francis A. Countway Library; 1921.

29. Bennett EH. Letter E.H. Bennett to R.W. Lovett, September 8, 1921Boston, Massachusetts: Francis A. Countway Library; 1921.

30. Gunther J. Roosevelt in Retrospect. New York: Harper and Co.; 1950.

31. Draper G. Letter G. Draper to R.W. Lovett, September 24, 1921Boston, Massachusetts: Francis A. Countway Library; 1921.

32. Draper G. Letter, G. Draper to R.W. Lovett, Oct.11, 1092. In: Lovett RW, edBoston, MA: Francis A. Countway Library; 19211921.

33. Lovett RW. Letter R.W. Lovett to E. H Bennett, Oct. 17, 1921. In: Bennett EH, edBoston MA Francis A. Countway Library;1921.

34. Lake K. Letter K. Lake to R.W. Lovett, December 17, 1921Boston, Massachusetts: Francis A. Countway Library; 1921.

35. Krida A. Letter A. Krida to R.W. Lovett, February 2, 1922Boston, Massachusetts: Francis A. Countway Library; 1922.

36. Lake K. Letter K. Lake to R. W. Lovett, Jan. 12, 1922. In: Lovett RW, edBoston MA Francis A. Countway Library; 19211922.

37. Lovett RW. Papers: Manual Muscle Test on Franklin D. Roosevelt, June 1, 1922Boston, Massachusetts: Francis A. Countway Library; 1922.

38. Draper G. Letter G. Draper to R. W. Lovett, February, 1, 1924Boston, Massachusetts: Francis A. Countway Library; 1924.

39. Asbury AK, Cornblath DR. Assessment of current diagnostic criteria for Guillain-Barre syndrome. Ann Neurol. 1990;27 Suppl:S21-24.

40. Bernsen RA, de Jager AE, van der Meche FG, Suurmeijer TP. How Guillain-Barre patients experience their functioning after 1 year. Acta Neurol Scand. Jul 2005;112(1):51-56.

41. Bernsen RA, Jager AE, Schmitz PI, van der Meche FG. Long-term sensory deficit after GuillainBarre syndrome. J Neurol. Jun 2001;248(6):483-486.

42. Burns TM. Guillain-Barre syndrome. Seminars in neurology. Apr 2008;28(2):152-167.

43. CDC. Poliomyelitis, paralytic case definition. 2012. Accessed January 18,2014.

44. Donaghy M. Brain's diseases of the nervous system. 12 ed. New York: Oxford University Press; 2009.

45. Draper G. Acute Poliomyelitis. York, Pennsylvania: P. Blakiston's Son \& Co.; 1916:1-149.

46. Horstmann DM. Clinical aspects of acute poliomyelitis. Am.J Med. 5/1949 1949;6(5):592-605.

47. Horstmann DM. Poliomyelitis: severity and type of disease in different age groups. Ann.N.Y.Acad.Sci. 9/27/1955 1955;61(4):956-967.

48. Ropper AH. The Guillain-Barre syndrome. N.Engl.J Med. 4/23/1992 1992;326(17):1130-1136.

49. Ropper AH, Samuels MA. Chapter 46 Guillain-Barre Syndrome. Adams and Victor's Principles of Neurology. 9th ed. NY, NY: McGraw-Hill Professional; 2009.

50. Sharrard WJ. Muscle recovery in poliomyelitis. The Journal of bone and joint surgery. British volume. Feb 1955;37-B(1):63-79.

51. Russell WR. Poliomyelitis; the pre-paralytic stage, and the effect of physical activity on the severity of paralysis. Br Med J. Dec 27 1947;2(4538):1023-1028.

52. Wiederholt WC, Mulder DW, Lambert EH. The Landry-Guillain-Barr'e-Strohl Syndrome or Polyradiculoneuropathy: Historical Review, Report on 97 Patients, and Present Concepts. Mayo Clin Proc. Jun 1964;39:427-451. 
53. Ruts L, Drenthen J, Jacobs BC, van Doorn PA, Dutch GBSSG. Distinguishing acute-onset CIDP from fluctuating Guillain-Barre syndrome: a prospective study. Neurology. May 25 2010;74(21):1680-1686.

54. Ruts L, Drenthen J, Jongen JL, et al. Pain in Guillain-Barre syndrome: a long-term follow-up study. Neurology. Oct 19 2010;75(16):1439-1447.

55. Weinstein L. Influence of age and sex on susceptibility and clinical manifestations in poliomyelitis. N Engl J Med. Jul 11 1957;257(2):47-52.

56. Adams, Graham MR. Neurodegenerative Diseases. In: Graham D, ed. Introduction to Neuropathology. 3 ed: Oxford University Press; 2006:331-344.

57. Solomon T. Encephalitis, and Infectious Encephalopathies. In: Donaghy M, ed. Brain's Diseases of the Nerovous System. New York: Oxford University Press; 2009:1355-1428.

58. Adams V. Chapter 3 Motor Paralysis and Patterns of Paralysis. In: Adams, Brain, eds. Adam's \& Victor's Principles of Neurology. 7th ed. New York NY: McGraw-Hill; 2000:39-54.

59. Weinstein L, Shelokov A, Seltser R, Winchell GD. A comparison of the clinical features of poliomyelitis in adults and in children. N Engl J Med. Feb 21 1952;246(8):297-302.

60. Peabody FW, Draper G, Dochez AR. A Clinical Study of Acute Poliomyelitisnumber 4. Monograph ed. New York: Rochefeller Institute for Medical Research; 1912:1-186. Available at: https://archive.org/details/cu31924000324784 Accessed 2/22/2016

61. Adams, Victor, eds. Chapter 3 Motor Paralysis and Patterns of Paralysis. 7th ed. New York NY: McGraw-Hill; 2000. Adams, Brain, eds. Adam's \& Victor's Principles of Neurology.

62. Lake K. Letter K. Lake to R.W. LovettBoston, Massachusetts: Francis A. Countway; 1922.

63. Roosevelt FD. Letter Franklin D. Roosevelt to Dr. Egleston, October 11, 1924. 1924; http://www.archives.gov/research/americans-with-disabilities/transcriptions/naid-6037479-letterfrom-fdr-to-dr-egleston.html. Accessed February 4, 2014, 2014.

64. Lovett RW. The treatment of infantile paralysis. York, PA: P. Blakiston's Son \& Co.; 1916:1-195, Available at https://archive.org/stream/treatmentofinfan00loveuoft/treatmentofinfan00loveuoft_djvu.txt Accessed2/22/2016

65. Draper G. Letter G. Draper to R.W. Lovett, October 17, 1921Boston, Massachusetts: Francis A. Countway Library; 1921.

66. Lovett RW. A plan of treatment in infantile paralysis. JAMA. 1916;67(6):421-426.

67. Halstad L, Weichers D. Introduction. Paper presented at: Late Effects of Poliomyelitis1985; Miami, FL.

68. Lenhard R. The Results of Poliomyelitis in Baltimore. JBJS AM. Jan 1943;25(1):132-141.

69. Landauer KS, Stickle G. An analysis of residual disabilities (paralysis and crippling) among 100,000 poliomyelitis patients: with special reference to the rehabilitation of postpoliomyelitis patients. Arch Phys Med Rehabil. Mar 1958;39(3):145-151.

70. Sharrard WJ. The distribution of the permanent paralysis in the lower limb in poliomyelitis; a clinical and pathological study. The Journal of bone and joint surgery. British volume. 1955;37(4):540-558.

71. Nissen KI. Poliomyelitis on St. Helena, 1945-6. Proceedings of the Royal Society of Medicine. Dec 1947;40(14):923-927.

72. Lovett RW. Letter R.W. Lovett to E.H. Bennett, September 3, 1921Boston, Massachusetts: Francis A. Countway Library; 1921.

73. Lovett RW. Letter, R.W. Lovett to George Draper, Sept. 26, 1921. In: Draper G, edFrancis A. Countway Library, Boston MA1921:1.

74. Ropper AH. Severe acute Guillain-Barre syndrome. Neurology. Mar 1986;36(3):429-432. 
TABLE 1

590

Serial manual muscle tests performed on Franklin Delano Roosevelt by R. W. Lovett (Lovett Papers; Francis A. Countway Library, Boston, Massachusetts)

593

\begin{tabular}{|c|c|c|c|c|c|c|c|c|}
\hline Left 1923 & & Left 1922 & & $\begin{array}{l}\text { Muscles Tested } \\
\text { Back and Legs }\end{array}$ & Right 1922 & & Right 1923 & \\
\hline Normal & 5 & Good & 4 & Back & Good & 4 & Normal & 5 \\
\hline \multirow[t]{2}{*}{ Poor } & 2 & Poor & 2 & Abdominal lateral & Poor & 2 & Fair & 3 \\
\hline & & Poor & 2 & Quadratus lumborum & Fair & 3 & & \\
\hline Poor & 2 & Poor & 2 & Gluteus maximus & Poor & 2 & Poor & 2 \\
\hline Trace & 1 & Trace & 1 & Iliopsoas & Poor & 2 & Poor & 2 \\
\hline Trace & 1 & Zero & 0 & Tensor fasciae latae & Trace & 1 & Poor & 2 \\
\hline Poor & 2 & Poor & 2 & Sartorius & Trace & 1 & Zero & 0 \\
\hline Poor & 2 & Poor & 2 & Hip abductors & Trace & 1 & Trace & 1 \\
\hline Poor & 2 & Poor & 2 & Hip adductors & Trace & 1 & Trace & 1 \\
\hline Poor & 2 & Poor & 2 & Quadriceps & Poor & 2 & Trace & 1 \\
\hline Poor & 2 & Poor & 2 & Inner hamstrings & Zero & 0 & Zero & 0 \\
\hline Zero & 0 & Zero & 0 & Outer hamstrings & Poor & 2 & Poor & 2 \\
\hline Poor & 2 & Trace & 1 & Gastrocnemius & Poor & 2 & Poor & 2 \\
\hline Zero & 0 & Zero & 0 & Anterior tibialis & Zero & 0 & Zero & 0 \\
\hline Zero & 0 & Trace & 1 & Posterior tibialis & Trace & 1 & Trace & 1 \\
\hline Poor & 2 & Trace & 1 & Peroneals & Fair & 3 & Fair & 3 \\
\hline Poor & 2 & Poor & 2 & Extensor digitorum longus & Fair & 3 & Poor & 2 \\
\hline Fair & 3 & Poor & 2 & Extensor digitorum brevis & Fair & 3 & Trace & 1 \\
\hline Poor & 2 & Poor & 2 & Extensor proprius hallucis & Fair & 3 & Fair & 3 \\
\hline Fair & 3 & Poor & 2 & Flexor longus & Poor & 2 & Poor & 2 \\
\hline \multirow[t]{2}{*}{ Fair } & 3 & Poor & 2 & Flexor brevis & Poor & 2 & Poor & 2 \\
\hline & & Poor & 2 & Flexor lumbricale & Poor & 2 & & \\
\hline Fair & 3 & & & Flexor halluces & & & Poor & 2 \\
\hline
\end{tabular}

The examinations in 1922 and 1923 used the designation of normal, good, fair, poor, and trace. These have been converted to the nearest number of $0-5$ ( 0 = zero; $1=$ trace; $2=$ poor; 3 =fair; $4=$ good; $5=$ normal), which is the current convention for manual muscle testing and permits ease of comparison. In addition, some muscles have been deleted or substituted in the hands or feet to allow comparison.

Reprinted from American Journal of Physical Medicine and Rehabilitation, Vol 81/8, John Ditunno and Gerald Herbison, Franklin D. Roosevelt: Diagnosis, Clinical Course, and Rehabilitation from Poliomyelitis/Manual Muscle Test of FDR Table, Jan 1, 2002, with permission from Wolters Kluwer Health, Inc. 
606

607

608

\title{
Table 2. Symptoms/Signs of FDR Case report, Poliomyelitis \& Guillain-Barre Syndrome (GBS)
}

\author{
Lower Extremity $=\mathrm{LE} ;$ Symmetrical $=$ Sym .
}

\begin{tabular}{|c|c|c|c|}
\hline SYMPTOMS \& SIGNS & FDR CASE REPORT & POLIOMYELITIS & GBS \\
\hline FEVER & Present 22,28 & Typical $^{42}$ & Absent $^{42}$ \\
\hline HYPERESTHESIA & $\begin{array}{l}\text { Thigh \& calves Onset - } \\
5 \text { months } \\
\end{array}$ & $\begin{array}{l}\text { Typical Up to 5-6 } \\
\text { months }\end{array}$ & $\begin{array}{l}\text { Dysesthesia fingers } \\
\text { and toes for years } 40 \text {, } \\
41,53\end{array}$ \\
\hline $\begin{array}{l}\text { MENIGEAL } \\
\text { IRRITATION }\end{array}$ & $\begin{array}{l}\text { Severe Back \& Leg } \\
\text { Pain } 22,26\end{array}$ & $\begin{array}{l}\text { Meningeal symptoms } \\
=\text { severe head, back \& } \\
\text { thigh pain } 50\end{array}$ & Uncommon \\
\hline $\begin{array}{l}\text { MUSCLE } \\
\text { TENDERNESS }\end{array}$ & $\begin{array}{l}\text { Present } \\
\text { weeks }^{63}\end{array}$ & $\begin{array}{l}\text { Very common } 24,59,60 \\
\text { duration } 4 \text { weeks to } 6 \\
\text { months }\end{array}$ & $\begin{array}{l}\text { Less common } \\
(11 \%)^{52}\end{array}$ \\
\hline \multicolumn{4}{|l|}{ MUSCLE WEAKNESS } \\
\hline DISTRIBUTION & $\begin{array}{l}\text { Scattered in UE } \\
\text { roughly sym. LE }\end{array}$ & $\begin{array}{l}\text { Typically scattered } \\
\text { roughly sym. }{ }^{24,60} \\
\text { Adults } 50 \% \text { both LE }\end{array}$ & Symmetrical ${ }^{48}$ \\
\hline RECOVERY & Minimal LE ${ }^{36}$ & Moderate & Maximal $^{52}$ \\
\hline $\begin{array}{l}\text { RESIDUAL } \\
\text { PROXIMAL VS } \\
\text { DISTAL WEAKNESS }\end{array}$ & Proximal > distal ${ }^{36}$ & Proximal > distal ${ }^{56,60}$ & $\begin{array}{l}\text { Distal; Rare proximal } \\
52\end{array}$ \\
\hline $\begin{array}{l}\text { SEVERITY \& } \\
\text { DISABILITY } \\
\text { USE OF BRACES } \\
\text { AND WHEELCHAIR }\end{array}$ & $\begin{array}{l}\text { Severe; Long Leg } \\
\text { Braces/Wheelchair }{ }^{14}\end{array}$ & $\begin{array}{l}\text { 5-20 \% Long Leg } \\
\text { Braces/Wheelchair } 66, \\
68\end{array}$ & $\begin{array}{l}\text { Not reported in Non- } \\
\text { Bulbar }^{74}\end{array}$ \\
\hline $\begin{array}{l}\text { OBJECTIVE SENSORY } \\
\text { FINDINGS }\end{array}$ & Absent ${ }^{26}$ & Absent $^{24,43}$ & Present $75 \%{ }^{48}$ \\
\hline FACIAL PARALYSIS & Present unilateral 22 & "Not uncommon"65 & Common $^{48}$ \\
\hline BLADDER PARALYSIS & $\begin{array}{l}\text { Present 3-4 wks. } \\
\text { duration } 66\end{array}$ & $\begin{array}{l}40 \% \text { in adults several } \\
\text { wks. duration } 58\end{array}$ & $\begin{array}{l}\text { Bladder problems } \\
30 \% 54\end{array}$ \\
\hline
\end{tabular}


610 Clinical features of Franklin D. Roosevelt's case compared with those of Guillain-Barre

611 syndrome (GBS) and poliomyelitis* (adapted from Goldman, 2003) ${ }^{1}$

\begin{tabular}{l|lll} 
CLINICAL FEATURES & ROOSEVELT'S CASE & GBS & POLIOMYELITIS \\
\hline Age of onset & 39 years & Mainly adults & Mainly young children \\
Flaccid Paralysis & Symmetric, ascending & Symmetric ascending & Assymetric \\
Progress of paralysis & $10-13$ days & $10-14$ days & $3-5$ days \\
Facial paralysis & Present & Common, bilateral & Rare, save in bulbar type \\
Bowel/bladder dysfunction & 14 days & $7-14$ days & $1-3$ days \\
Numbness & Present & Common & Absent \\
Dysaesthesia & Protracted & Protracted & Absent \\
Meningismus & Absent & Absent & Common \\
Fever & Present & Rare & Common \\
Recovery from paralysis & Symmetric, descending & Symmetric, descending & Assymetric \\
Permanent paralysis & Symmetric & In about $15 \%$ of cases & In about 50\% of cases \\
\hline
\end{tabular}

612 *The clinical features of poliomyelitis and GBS have been drawn from many past publications

613 Reprinted from Journal of Medical Biography, Vol 11/4, Armond S Goldman, Elisabeth J

614 Schmalstieg, Daniel H Freeman, Jr, Daniel A Goldman, Frank C Schmalstieg, Jr., What was the

615 Cause of Franklin Delano Roosevelt's Paralytic Illness?/ Table 1, 203, 11/01/2003, with

616 permission from Sage Publications.

617

618 


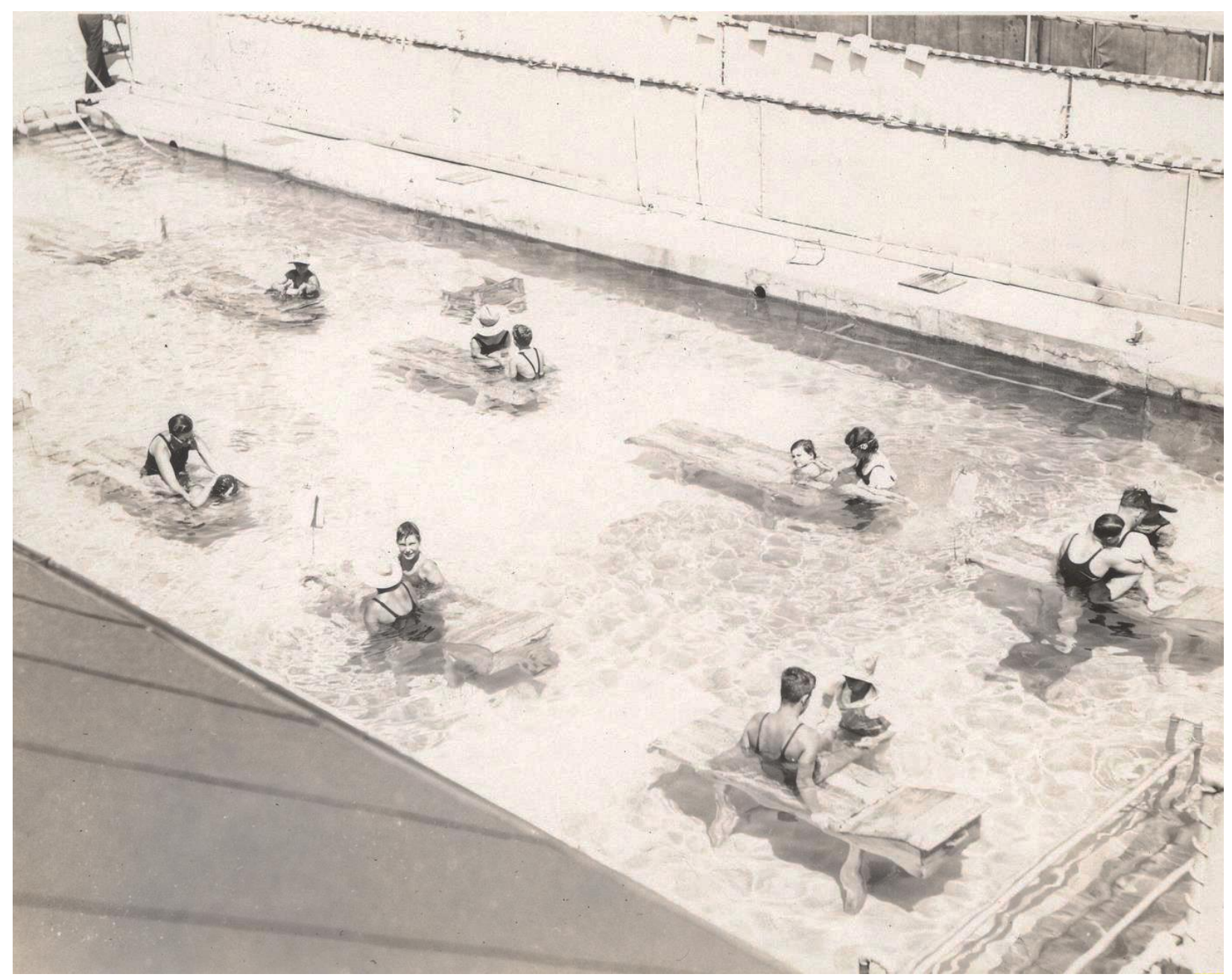

Figure 1. A Day in the Therapy Pools in Warm Springs (1935) 


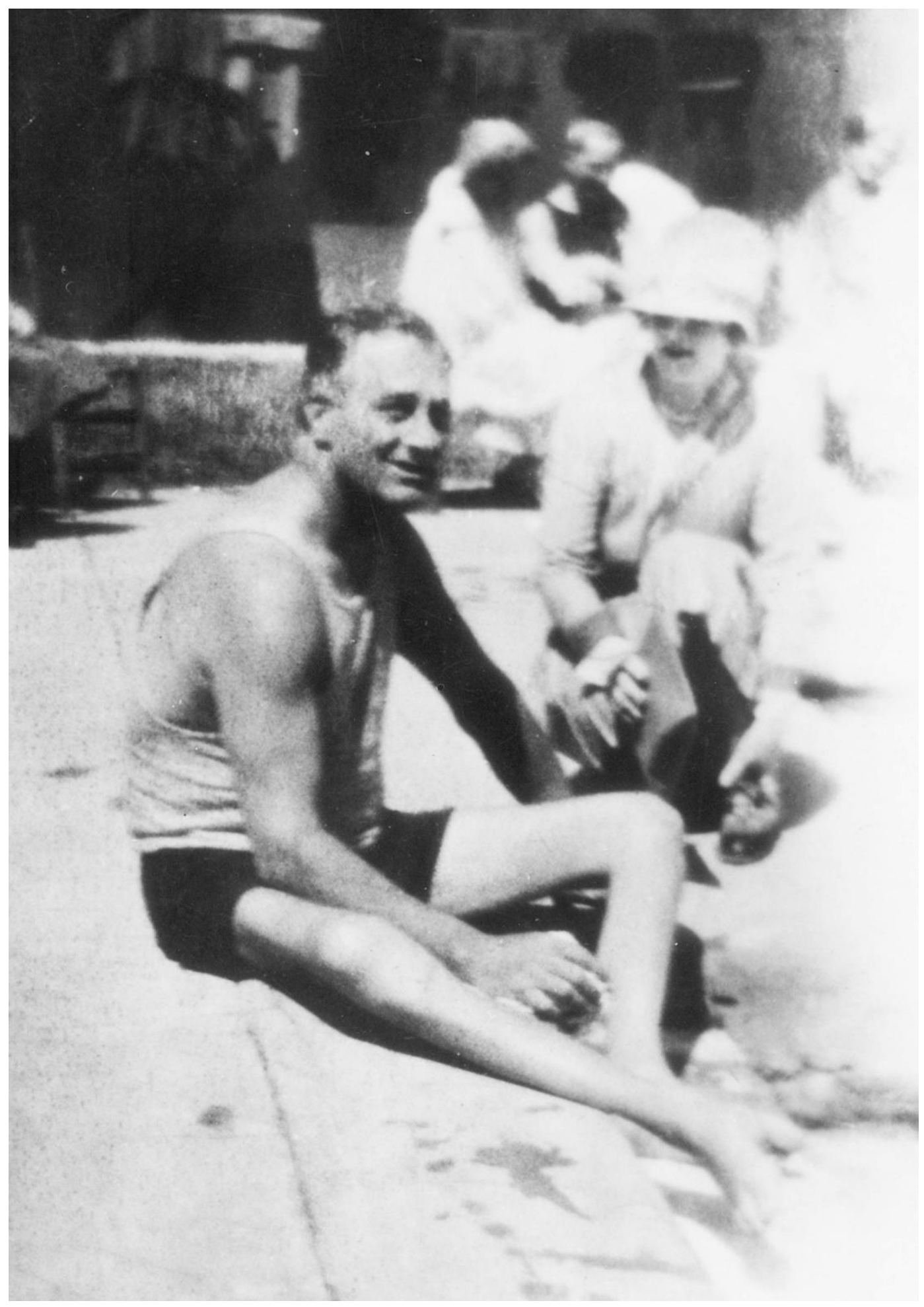




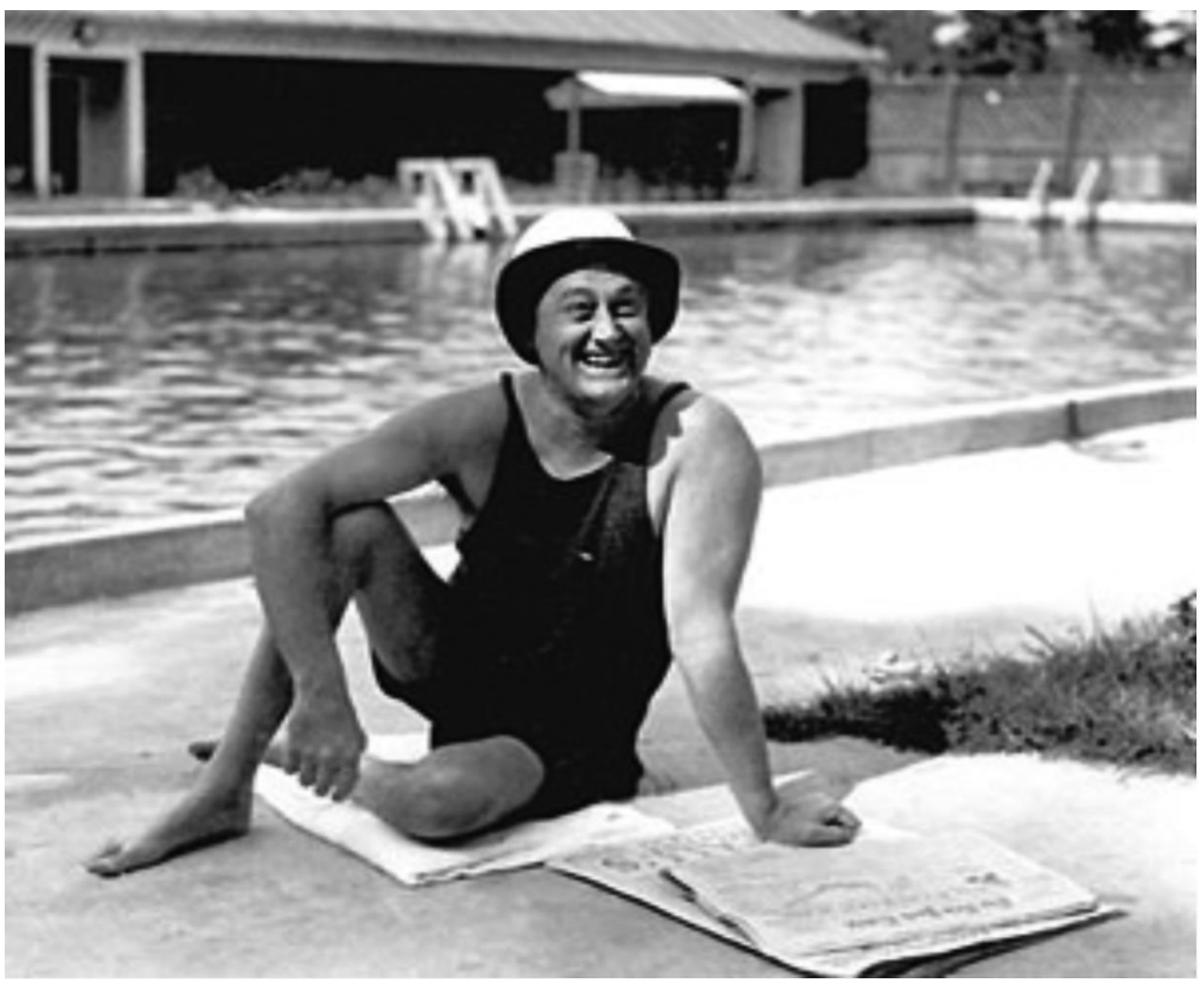

Figure 3. FDR again showing proximal \& distal LE atrophy (c1932) 


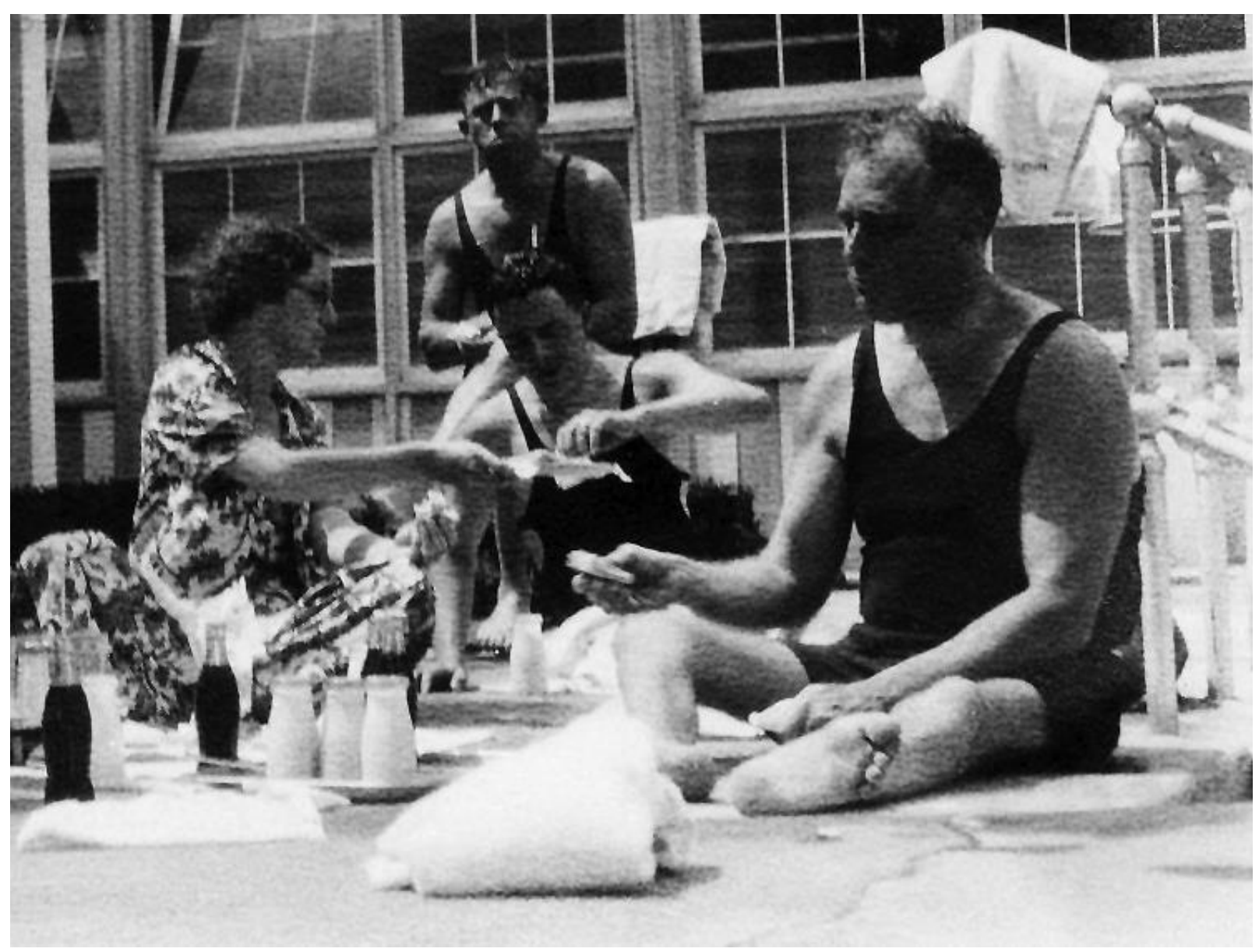

634

Figure 4. FDR eating Poolside Lunch showing LE Atrophy (1932)

Photo credit Warm Springs Vocational Rehabilitation Campus 